\title{
Mixed Impressions. Respectable Work and Slow Progress in the Science of Personnel Management within German Speaking Countries
}

In 1961, i.e. 50 years ago, the first chair in personnel management was established at university level in Germany. This marks a good occasion to ask for the results of scientific research in the German speaking countries on the topic of personnel management. Can we observe significant advances in knowledge since then? What are the contents, the methods and the styles of the theoretical analyses and the empirical investigations on this highly contested terrain of economic reality? These questions were the main themes in the $8^{\text {th }}$ annual conference of the "AKempor: Arbeitskreis für empirische Personal- und Organisationsforschung" (Working Group on Empirical Personnel and Organizational Studies). In this special issue we present five contributions of this conference which consider the main problems with a science of personnel management, namely the explanation of the employee's behavior on the one side and the explanation of the employer's behavior at the other side. The issue considers the theoretical base of personnel management and the ideological functions that the contributions of personnel management scientists may have.

\section{Advances in knowledge}

Advancement in knowledge is the most important aim in science. We want to understand the world, therefore we look for explanations. It is not so much the explicandum (the thing we want to explain) but the explicans we are interested as researchers. The explicans is the rule which connects the empirical observable phenomena and it is the core object of scientific progress: "Thus, scientific explanations, whenever it is a discovery, will be the explanation of the known by the unknown." (Popper, 1972, p. 191). Undoubtedly there are some other aims of science beside explanation and there is some dispute about the most important tasks of a scientist, as well as what would be the best way to carry out these tasks. Whichever philosophy of science one may prefer, there should be unanimous consent that at the base of all science lies good knowledge and - notwithstanding that (scientific) knowledge always will be imperfect - we should try to improve it (Bunge, 1983).

The improvement of knowledge manifests itself in the discovery of new facts, in studying the substance of exciting hypotheses, in the development of profound theories, and in gaining more realistic images of the world. In other words: in the unmasking of unfounded intellectual claims and in preventing ideological appropriations of

\footnotetext{
* Prof. Dr. Albert Martin, Institute for Small and Medium Sized Enterprises, University of Lueneburg, Campus, D - 21391 Lueneburg, Germany, Phone: ++49-4131-6772130.

E-Mail:martin@uni-lueneburg.de.
} 
interpretation prerogatives. The articles in this issue provide their own answers to these questions. In the following I want to present some more considerations about the developments of research on personnel management. Admittedly they rest on my personal assessments, but they should nevertheless hold some truth and perhaps can stimulate further discussions and - if controversial - be subjected to more rigorous investigations.

\section{Disappointing aspects}

I perceive that one has to register positive as well as negative aspects in the research on personnel management. The most prominent negative aspect is the lack of genuine own theoretical achievements in German literature on this topic. In general most research is carried out without any deeper connection to theoretical elaborations and if theoretical approaches are adopted they normally stem from other branches of the behavioural sciences (especially from the Anglo-Saxon literature). It therefore comes as no surprise that one seldom, if ever, can find a systematic comparison regarding the value of competing theories. This is a task which would include the design of sophisticated empirical studies. Often researchers are content with so called conceptual frameworks, i.e. with a collection of loosely coupled ideas, a preliminary listing of variables and some vague suggestions regarding possible connections between these variables. The resulting verbal constructions may give a superficial cognitive order but more often than not they remain noncommittal promises for further inquiries which cannot really serve as conclusive foundations for empirical investigations.

Correspondingly the role of theory in empirical investigations is often dubious. Every serious test of theories (and hypotheses) requires the formulation of a theoretical (test-) model which explicitly specifies the logical connections between all relevant constructs, antecedent conditions, auxiliary hypotheses and simplifying assumptions (c.f. for example Bunge, 1967). The reality of empirical studies falls short of these requirements. Very often the gap between theoretical and empirical propositions is considerably large. Theories are frequently only "used" to give a rough overview about the background from which the authors argue. This being as it may, the most empirical investigations in the realm of personnel management are actually not about theory testing but - at best - about theory-illustration. The aspiration is not to criticize and improve theories, instead the authors are often satisfied when they can make sense of their data with the help of some loosely coupled theoretical considerations. For them theory is primarily a method which can deliver interpretive patterns - an attitude, which gives the researcher a wide array of subjective construal. Theories do, after all, play a role even in this reduced version of scientific enterprise. But more often than not the researchers seem to have no theoretical interest at all. Many brave empiricists are content with data-mining and with collecting intrinsically unconnected hypotheses. Some colleagues cultivate the enjoyment that virtuosic methodical exercises can deliver, which can perhaps serve the need for methodological rigor but regrettably is normally hostile to the aim for exploring the deep-rooted mechanisms which govern economic life. It must of course be noticed that all these critical methodological deficits are not characteristics of only the German literature but for literature on personnel management as a whole. 
Some light on the advancement of a coherent knowledge base is shed by answering the question of the interconnectedness of research. In 1987 the meanwhile most important scientific journal about personnel management, the "Zeitschrift für Personalforschung, ZfP" ("German Journal of Research in Human Resource Management") was founded. Up until 2010 it contained 408 articles, 160 of them empirical. In 124 articles one can find one or more quotations drawn from other articles in this journal. In 46 of the 160 empirical articles one or more other articles of the ZfP are quoted whereby 15 refer to other empirical studies published in this journal (but without always comparing the own results with those of the cited article). The most cited article (7 times) is from Hartmut Wächter about the research tasks in personnel management, next follows an article ( 5 times cited) from Armin Töpfer about tasks in personnel research. Table 1 shows how often an article in the ZfP is cited in the other articles of the ZfP. Apparently the research articles do not cluster around some core publications, theories or empirical findings, instead the publications mirror a rather fragmented research field.

Table 1: Number of quotations an article receives in the "Zeitschrift für Personalforschung" (ZfP) by other articles of the ZfP

\begin{tabular}{c|c}
\hline \multicolumn{2}{c}{ Number of articles which are cited } \\
\hline 7 times & 1 \\
\hline 6 times & 0 \\
\hline 5 times & 1 \\
\hline 4 times & 6 \\
\hline 3 times & 10 \\
\hline 2 times & 22 \\
\hline 1 times & 93 \\
\hline never & 275 \\
\hline sum & 408 \\
\hline
\end{tabular}

A special German problem lies in the small quantitative output. Between the years 1977 and 1984 the number of empirical studies on the topic of personnel management in the three most important German scientific journals on Management ("Zeitschrift für Betriebswirtschaft", "Schmalenbachs Zeitschrift für betriebswirtschaftliche Forschung", "Die Betriebswirtschaft") was rather small (3.8 articles a year, Martin, 1989). Since then this number has risen, and one can find in 2007, for example, eight articles in the three journals mentioned above. Thus a main obstacle for revolutionary steps onward in the growth of personnel management science surely lies in the small number of personal management researchers in the German speaking countries. So for example in 1977 there were only 11 people in the group of university professors in Germany, Austria and Swiss that had their first denomination in personnel management. This number grew to 30 in 1995 and in 2008 amounted to 22 (Oechsler, 2001; Oechsler, Walter, \& Emamalizadeh, 2009). 


\section{Positive aspects}

In other words a balanced evaluation of the performance of a scientific discipline requires not only to look at the output, but at the input as well. With few resources one should not expect overwhelming performance. The quantitative side, particularly in a profession like science, is also of no real relevance and therefore one should consider primarily the qualitative side. This is of course no simple task. If one - as above takes the aim of science as the main criterion (general and corroborated theories which entail fundamental and deep mechanisms of organizational processes) the assessment is not very positive. If one, however, looks at some other important aspects of good scientific practice, one may come to a more favourable assessment. In German speaking countries a good tradition existed (which regrettably eroded in the last years). This tradition demanded from those who wanted to proceed in their academic career, that they wrote a second dissertation ("Habilitationsschrift") which should be more deep-routed and more powerful than the first dissertation. These dissertations were as a rule well informed texts, they referred to the most important theories of their subject, and often entail well designed empirical studies. They were written in a discursive manner and often offered good advice for further fruitful research. On the other hand, they often remained isolated pieces of work and it was very seldom that they established a more enduring research programme. The authors often turned to new themes and to minor work. Another positive aspect of personnel management research in German speaking countries is in regard to its topics. To be sure, many studies in Germany follow - as in other countries too - the fads and fashions of short-term (research-) political excitements. Despite this, one can also find beside these engagements good research on topics that has fundamental and far-reaching meaning. Examples are investigations about the character of the employment relationship, incentive policies, the role of German specific institutions in industrial relations, the qualifying efforts of firms, the handling of migration problems, and the interplay of strategic and human resources policies of enterprises. This work is admittedly carried out on a small base, but theoretically is often on a high level.

Another positive aspect is the quality of many textbooks in German language on personnel management. One can certainly find books which are very superficial, affirmative, and embarrassing, but one can also find plenty of books which are reflective, critical and thought-provoking. And it is not the last task of scientific based texts to promote the enlightenment of their readers, so in finding a balance one comes to a mixed assessment. On an individual level one finds much respectable work, but the advancement of theory is rather slow.

\section{Contributions in this issue}

In the first article Dudo von Eckardstein and Stefan Konlechner deal with German and Austrian research (and teaching) on employer behavior ("Arbeitgeberverhalten"). The two authors explain that the general public is well informed about important aspects of employer behavior and they examine whether this fact finds it expression in scientific textbooks and journal publications. Their analysis shows, among other things, that some of the new developments in the field of human resource management do not receive the appropriate attention in research and teaching. It also shows that bad prac- 
tices are seldom discussed and are sometimes even declared to be good practices. Another result of their analysis shows that research most often describes the practices of employers in isolation and that one can find only small efforts to create taxonomies in order to classify employer behavior.

Hartmut Wächter essentially agrees with the analysis of Eckardstein and Konlechner. The Marxian approach asserts that in order to understand the behavioral practices of an employer, it is better not to concentrate on his individual motivations but to the structural constraints which canalize his behavior. One can, however, find good examples regarding the importance of the attitudes and behaviors of employers who act very differently even when they are confronted with very similar economic situations. Wächter concludes that German textbooks suggest a world of work without conflicts and ignore the scope of action employers have in spite of collective bargaining agreements. Wächter recommends that more and more intensive studies on personnel management in the context of industrial relations should be carried out. He explicates the fruitfulness of such projects by referring to some interesting examples.

Alexander Dilger describes strengths and weaknesses of personnel economics as a sub-discipline of human resource management. Personnel economics use microeconomic approaches and methods to analyze the personnel function. Dilger identifies as the strengths of the economic approach its clear and methodological foundation, its scientific achievements, its rediscovery of the importance of cost-aspects in the employment relationship and its connections to other disciplines. Possible weaknesses of the personnel economic approaches may be found in its sometimes meager informational content, its simplifications and in deficits regarding moral issues. In considering the relationship of personnel economics with other approaches Dilger argues that an applied science such as human resources management cannot be a genuine scientific discipline and he contends that because of its merits personnel economics should take the role of the leading discipline.

Lutz von Rosenstiel gives an overview about scientific research on individual behavior in organizations. He discusses a number of reasons why it is difficult to obtain a coherent body of knowledge about this topic, some of them meta-theoretical and methodological, others political, organizational and ideological (to name but a few: the existence of different schools of psychology, one-sided and interest-laden views, the dominance of survey methodology, measurement problems, the submission of researchers to dominant styles of publishing). Von Rosenstiel reports on main insights about the effects of stable and variable personal traits, and of situational conditions on employee behavior and about practical consequences. He concludes: "When trying to get an overview, one ends up with an ambivalent opinion." There is a lot of wellfounded knowledge, especially about the aptitudes of employees, but on the other hand one finds remarkable ignorance on behaviour which has no direct relation to performance and on the impacts of specific work and organizational conditions.

Werner Nienhueser argues in his article that empirical work in human resource management often creates a wrong image of reality and therefore produces ideology. Propositions are ideological if they are immunized against criticism and if they are strategically used to serve one-sided interests. To provide evidence for his thesis, Nienhueser makes five points. Thus for example one has to notice high selectivity re- 
garding topics and questions. Furthermore HRM research is very narrowly focused on performance and on practices which are supposed to affect performance. In accordance with most other authors of this issue Nienhueser states that bad practices are widely ignored in the scientific community. Moreover HRM research is characterized by one-sided evaluations, in most cases it is about the organizational elite and aimed at serving the interests of that group. Methodological problems in getting access to reliable information (e.g. resulting from the gatekeeper function of management), may foster the ideological misery.

\section{References}

Bunge, M. (1967). Scientific Research. 2 Volumes. New York: Springer.

Bunge, M. (1983). Treatise on Basic Philosophy. Volume 6: Epistemology and Methodology II. Dordrecht: D. Reidel.

Martin, A. (1989). Die empirische Forschung in der Betriebswirtschaftslehre. Stuttgart: Poeschel.

Popper, K.R. (1972). Objective Knowledge. Oxford: Clarendon Press.

Oechsler, W.A. (2001). Entwicklungen von Professuren und Habilitationen in der Betriebswirtschaftslehre 1998-2001. Wirtschaftswissenschaftliches Studium, 30(8), 393-395.

Oechsler, W.A., Walter, C., \& Emamalizadeh, K. (2009). Entwicklung von Professuren im Fach Betriebswirtschaftslehre 2008-2011. Forschungsbericht der Fakultät für Betriebswirtschaftslehre, Nr. 2009-1. Universität Mannheim. 